\title{
Development of a Modified - release Drug Delivery System with Bexarotene Loaded in Clinoptilolite
}

\author{
LACRAMIOARA OCHIUZ ${ }^{1 *}$, CRISTINA GHICIUC ${ }^{2 *}$, MARIA IGNAT ${ }^{3 *}$, MARCEL POPA ${ }^{4}$, CATALINA ANISOARA PEPTU ${ }^{4}$, \\ AURELIA VASILE ${ }^{3}$ \\ ${ }^{1}$ Grigore T. Popa University of Medicine and Pharmacy from Iasi, Faculty of Pharmacy, 16 Universitatii Str., 700115, lasi, Romania \\ ${ }^{2}$ Grigore T. Popa University of Medicine and Pharmacy of lasi, Faculty of Medicine, Department of Pharmacology, 16 Universitatii \\ Str., 700115, Iasi, Romania \\ ${ }^{3}$ Alexandru Ioan Cuza University from lasi, Department of Chemistry, 11 Carol I Blvd., 700506, lasi, Romania \\ ${ }^{4}$ Gheorghe Asachi Technical University of lasi, Department of Natural and Synthetic Polymers,73 Prof. Dr. Docent Dimitrie \\ Mangeron Av., 700050, lasi, Romania
}

\begin{abstract}
Developing biomaterials with optimal loading properties and controlled release of drugs is a priority of medical research. Clinoptilolite is a natural zeolite used in various industrial processes. Its texture and structure recommend its use as a biocompatible matrix for the development of modified release drug delivery systems. The present study aims to develop and characterize modified-release systems based on bexarotene loaded clinoptilolite. Bexarotene is a retinoid that is used as an anticancer agent in the topical treatment of cutaneous T-cell lymphoma. By adding bexarotene to these systems, skin delivered antineoplastic therapy with bexarotene can be improved. Clinoptilolite was obtained by purifying the volcanic tuffs from Mirsid quarry, Salaj Romania. After thermal and chemical purification, two monoionic forms of clinoptilolite were obtained. They were labeled as $\mathrm{Na}-\mathrm{CLI}$ and $\mathrm{H}-\mathrm{CLI}$, respectively. Their texture and structure were characterized by specific methods. Subsequently, these forms of clinoptilolite were used as hosts for bexarotene loading by wet impregnation. The obtained results showed that the two modified-release systems Bxt@Na and Bxt@H, respectively, have no incompatibilities and provide prolonged release of the drug.
\end{abstract}

Keywords: clinoptilolite, bexarotene, modified-release drug delivery system

Bexarotene (4- [1- (5,6,7,8-tetrahydro-3,5,5,8,8pentamethyl-2-naphthalenyl) ethenyl] benzoic acid (Bxt) is a well-known antineoplastic agent that is used in the topical treatment of cutaneous T-cell lymphoma. Bexarotene is a retinoid that selectively activates the retinoid X receptors (RXRs) and induces cell differentiation and apoptosis. Moreover, ithas the advantage of preventing the development of drug resistance [1].

Nevertheless, like most topical antineoplastic drugs, bexarotene has adverse effects such as irritant dermatitis, pruritus, pain, skin inflammation and local excoriations. This has required finding dosage forms that could eliminate or significantly reduce local adverse effects. The controlledrelease drug delivery system with targeted delivery of the drug directly to the affected organ is one of those dosage forms.

The present study suggests a controlled/modified drug delivery and release system of bexarotene directly into the cutaneous lesion. It was prepared through immobilization on biocompatible nanoporous inorganic hosts such as natural clinoptilolite.

Natural zeolites are hydrated alkaline or alkaline-earth aluminosilicates with an open crystalline structure having high hydrothermal stability, molecular sieve properties, adsorbent and catalytic properties and ion exchange properties. They have well-known applications in industry, agriculture and environmental protection. It is worth noting that clinoptilolite is a natural zeolite with important biomedical applications.

Due to the fact that it is nutritionally inert, clinoptilolite is used as a non-toxic absorbent for toxins originating from feed. Its absorption into the gastrointestinal tract prevents these toxins from passing into the circulatory system, thereby protecting the animals [2 - 4]. Various studies have also shown that purified natural clinoptilolite is harmless to the human body [5]. Therefore, it is used as an antidiarrheal drug [6] and as an antacid showing no toxic effects or biological hazards $[7,8]$.

One of the current most advanced uses of clinoptilolite is its application as a delivery matrix for active ingredients in antineoplastic therapy $[9,10,11]$. Zeolites can be modified to enhance their performance for the biomedical use as a target therapy due to the following properties: crystalline structure, the porosity caused by the channel system of constant size, exchangeable cations and reversible hydration.

Clinoptilolite (CLI), a natural zeolite that is isostructural with heulandite (HEU), is a microporous crystalline aluminosilicate with open structure, having the silicic ratio $\mathrm{Si} / \mathrm{Al}>4$, predominant alkaline cations $(\mathrm{Na}+\mathrm{K}>\mathrm{Ca}$ ) and the following chemical composition [12]:

$$
\left\{\mathrm{Na}_{1.84} \mathrm{~K}_{1.76} \mathrm{Mg}_{0.2} \mathrm{Ca}_{1.24}\left(\mathrm{H}_{2} \mathrm{O}\right)_{21.26}\right\}\left[\mathrm{Si}_{29.84} \mathrm{Al}_{6.16} \mathrm{O}_{72}\right. \text { ] }
$$

The volcanic tuft used in the present study contains up to $70 \%$ clinoptilolite. Itwas mined in the Mirsid quarry (Salaj County), Romania and it has the following average chemical composition: $\mathrm{SiO}$ 68.12\%-70.06\%; Al $\mathrm{O}, 11.77 \%$ 12.62\%; Fe O 0.67\%-1.06\%; CaO 3.36\%-4.82\%; MgO $0.55 \%-0.82 \%$; $\mathrm{K}_{2} \mathrm{O} 2.20 \%-3.52 \%$; $\mathrm{Na}_{2} \mathrm{O} 0.40 \%-0.60 \%$; $\mathrm{TiO}_{2}$ $0.18 \%-0.24$.

Due to the unique properties of clinoptilolite and, most of all, the possibility to modify it for an increased performance in the targeted delivery, clinoptilolite is likely to make a significant contribution to the pharmaceutical industry and medicine in the near future.

The natural product from the Mirsid quarry (Salaj) was exposed to various thermal and chemical treatments. From 
this, the $\mathrm{Na}^{+}$monoionic form, marked as $\mathrm{Na}-\mathrm{CLI}$, and the $\mathrm{H}^{+}$monoionic form, marked as $\mathrm{H}-\mathrm{CLI}$, were prepared. After their structure and texture were characterized, they were used as host/carrier for bexarotene.

The modified-release drug delivery systems (MRDDSs) with bexarotene were characterized and then subjected to the in vitro release assay. The in vitro release kinetic profile of bexarotene was evaluated using established mathematical models.

\section{Experimental part}

Materials and methods

The following materials were used in the study: bexarotene (Bxt, 98\%, Zhejiang Sanmen Hengkang China Pharmaceutical Co. Ltd.); ammonia solution ( $\mathrm{NH}_{3} \mathrm{~min}$. $25 \%$, Chemical Company, RO), hydrochloric acid ( $35-38 \%$, for analysis Chemical Company, RO), oxalic acid dihydrate (99\%, for analysis Chemical Company, RO), sodium hydroxide (for analysis Chemical Company, RO), dimethyl sulfoxide (Sigma).

All reagents were used without purification. The deionized water was obtained from the Milli-Q water purification system, Elga Pure Lab. The following reagents were used for the HPLC analysis: trifluoroacetic acid (TFA) (Merck, Germany); acetonitrile (ACN) chromatographic purity (Merck, Germany); glacial acetic acid (Merck, Germany); potasium phosphate (Sigma Aldrich, Germany), alcohol (pro analysis, Sigma Aldrich, Germany) double distilled water: Millipore, conductivity $-0.01 \mu \mathrm{S} / \mathrm{cm}$.

\section{Purification of natural clinoptilolite and preparation of monocationic forms of MRDDS}

Due to the fact that clinoptilolite is found in nature, as a major component of volcanic tuffs, the mined rock (from the Mirsid quarry, Salaj) was subjected to mechanical, thermal and chemical treatments to obtain a purified, clinoptilolite-rich product that can be used in the adsorption, catalytic, ion exchange, separation or biomedical processes.

Portions of the sample of purified volcanic tuff were subjected to the two-step ion exchange process to obtain the monocationic forms $\mathrm{Na}^{+}$(marked as $\mathrm{Na}$ ) and $\mathrm{H}^{+}$ (marked as H). The samples prepared in this way were used to prepare MRDDS systems by loading bexarotene.

\section{Drugloading}

The immobilization of bexarotene was achieved by incipient wet impregnation, using DMSO as a solvent. For this purpose, $0.5 \mathrm{~g}$ of $\mathrm{Na}$ monocationic matrix and $\mathrm{H}$ monocationic matrix, respectively, was contacted with 5 $\mathrm{mL}$ of Bxt $30 \mathrm{mg} / \mathrm{mL}$ solution and maintained for $12 \mathrm{~h}$ with slow magnetic stirring at room temperature. After separation and washing, the samples were dried at room temperature in the dark and they were marked as Bxt@Na and Bxt@H, respectively.

\section{HPLC assay}

The amount of retained Bxt was determined using the HPLC method, developed validated verified and revalidated in house with a HPLC Dionex Ultimate TM 3000 system (Thermo Fisher Scientific Inc., USA) equipped with a UVVIS Diode Array Detector, a Hypersil GOLD column (Thermo Fisher Sciencific Inc., USA), 4.6x 150 mm, 5um and a universal precolumn (Thermo Fisher Sciencific Inc., USA). Chromatogram recording was performed at $\lambda=262$ $\mathrm{nm}$; linearity ranging from 0.1 to $1 \mathrm{mg} / \mathrm{mL}$; the equation of the calibration curve, $y=934.49 x+0.986$; the detection limit $0.00822 \mathrm{mg} / \mathrm{mL}$ and the limit of quantification $0.02491 \mathrm{mg} / \mathrm{mL}$.

\section{Characterization of texture}

The clinoptilolite structure was determined by the X-ray diffraction method. X-ray diffractograms were recorded with a Panalytical X'Pert Pro MPD diffractometer using the CuK, radiation in the range of $2 \theta=5-60^{\circ}$.

The characteristics of the texture (specific surface and porosity) in the two monocationic matrices, before and after Bxt loading, were determined by the nitrogen adsorption method at a temperature of $77 \mathrm{~K}$ using a Quantachrome Nova 2200e Surface Area \& Pore Size Analyzer. Prior to the measurements, the samples were degassed under a high vacuum for $12 \mathrm{~h}$ at room temperature. The specific surface area $\left(S_{\text {o }}, \mathrm{m}^{2} / \mathrm{g}\right)$ was calculated from the linear portion of the isotherm by the Brunauer-Emmett-Teller multipoint method (BET). The volume of liquid nitrogen adsorbed at relative pressure $\mathrm{P} /$ $\mathrm{P}_{0}=0.95$ was used to estimate the total pore volume (TPV, $\mathrm{cm}^{3} / \mathrm{g}$ ).

FTIR spectra were recorded on a Bruker Tensor 27 equipped with a spectrometer having a DigiTectTM detector. Registered spectra were obtained on $\mathrm{KBr}$ pellets containing prepared samples, in the range of $400-4000$ $\mathrm{cm}^{-1}$ with a resolution of $2 \mathrm{~cm}^{-1}$ at room temperature.

\section{In vitro dissolution study}

Given the very low solubility of Bxt in water or phosphate-buffered saline (PBS) $[13,14]$, the in vitro dissolution tests of Bxt in the Bxt@Na and Bxt@H systems were performed using as a solvent medium a mixture of ethyl alcohol:phosphate saline buffer (EtOH:PBS) in a 3:1 ratio. The test was performed on a SR8 Plus Series $(A B \& L$ JASCO, Chatsw orth, CA, USA) apparatus 2 (paddles) equipped with a Dissoette autosampler (Hanson Research Corporation, Chatsworth, CA, USA) according to the following protocol: a specific amount of MRDDS containing $50 \mathrm{mg}$ of Bxt was introduced into containers having 100 $\mathrm{mL}$ of dissolution medium, with a bath temperature of 37 $\pm 0.5^{\circ} \mathrm{C}$, rotation speed $50 \mathrm{rpm}$; the sampling interval was set at 30 min during the first hour of the test, and at $60 \mathrm{~min}$ for the next $12 \mathrm{~h}$, respectively. Aliquots $(3 \mathrm{~mL}$ ) were withdrawn and subjected to HPLC analysis in order to determine the amount of Bxt released. After every sampling, the aliquots were replaced with equal volumes of medium at $37^{\circ} \mathrm{C}$. The amount of released Bxt in the dissolution media was assessed by the HPLC-DAD method described above.

\section{Results and discussions}

The structural analysis showed that the samples of purified natural clinoptilolite (clinoptilolite rich vulcanic tuff) had a crystalline structure that was not destroyed after the thermal and chemical treatments applied for purification purposes. Figure 1 shows the X-ray diffractogram for the purified clinoptilolite in which clinoptilolite was identified according to the JCPDS card 25-1349. Clinoptilolite is associated with some crystalline impurities, such as illite, quartzand feldspar. Chemical and thermal treatments were used for the partial removal of amorphous and crystalline impurities, without degrading the crystalline structure of clinoptilolite.

The textural properties (specific surface area, $\mathrm{S}_{\mathrm{BET}}$, pore volume, $\mathrm{V}_{\mathrm{n}}$ ) of the $\mathrm{Na}$ and $\mathrm{H}$ monocationic sample, and of the Bxt@Na and Bxt@H system, respectively are shown in table 1. 


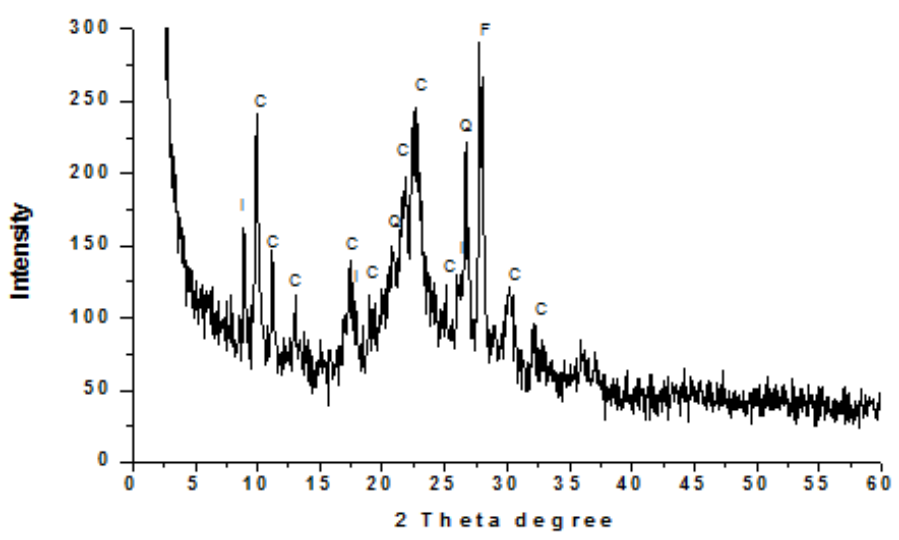

Fig. 1. Diffractogram of the sample of purified clinoptilolite:

C - clinoptilolite; I - illite; Q - quart; F - feldspar

Table 1

TEXTURAL PROPERTIES OF NANOPOROUS HOSTS

\begin{tabular}{|c|c|c|}
\hline Sample & SBET, $^{2} / \mathbf{g}$ & $\mathbf{V}_{\mathbf{p}, \mathbf{c m}^{3} / \mathbf{g}}$ \\
\hline $\mathrm{Na}$ & 46 & 0.0681 \\
\hline $\mathrm{Bxt} @ \mathrm{Na}$ & 22 & - \\
\hline $\mathrm{H}$ & 57 & 0.0861 \\
\hline $\mathrm{Bxt} @ \mathrm{H}$ & 33 & - \\
\hline
\end{tabular}

Regardless of the cationic form, clinoptilolite showed type I adsorption isotherms, characteristic of microporous materials (according to the IUPAC classification [15]), with inflection and sudden increase in the amount of nitrogen adsorbed in the area of relatively high pressures, $\mathrm{p} / \mathrm{p} 0>$ 0.80 and a narrow H3 hysteresis (IUPAC), as shown in figure 2. The sudden increase in the amount of nitrogen adsorbed at high relative pressure is due to the secondary porosity (the capillary condensation of nitrogen in the space between particles).

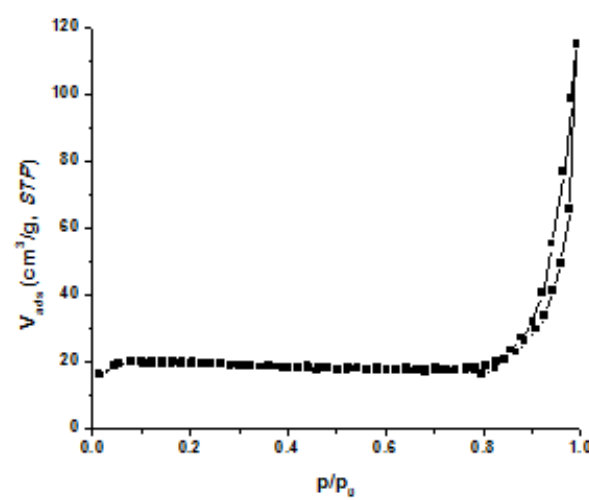

a

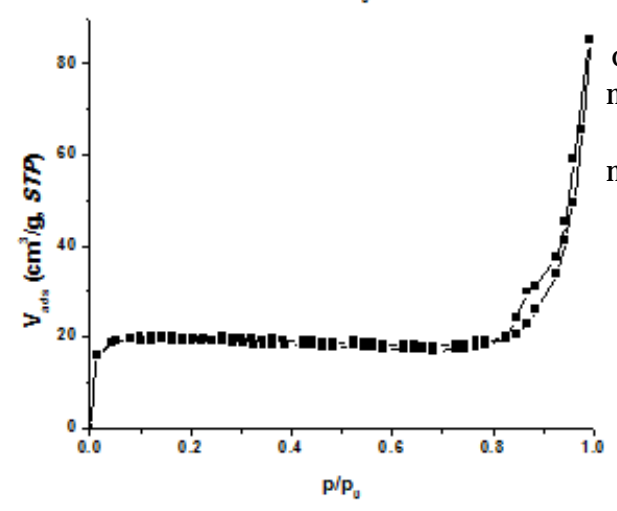

Fig. 2. Nitrogen adsorption isotherms characteristic of $\mathrm{H}$ monocationic form (a) and $\mathrm{Na}$ monocationic form (b), respectively.
The presence of bexarotene in the studied MRDDSs was shown by IR spectroscopy (fig. 3). Literature data on FTIR spectra for Bxt are very scarce, incomplete and they differ from one manufacturer to another. That is why an accurate comparison with the data obtained from the sample used in this study would be pointless. Added to this, the amount of Bxt found in the pores of each MRDDS obtained is small as compared to the zeolitic host, the vibrations of the components overlap and the resulting absorption bands are difficult to accurately assign.

Nevertheless, the spectra shown in figure 3 for the systems Bxt@H and Bxt@Na, respectively show changes in the $1600-1300 \mathrm{~cm}^{-1}$ region, due to the presence of Bxt molecules (the $1669 \mathrm{~cm}^{-1}$ band could be assigned to the stretch vibration of the carbonyl group); (ii) the $1390 \mathrm{~cm}^{-1}$ band is due to the symmetric bending vibration of the $-\mathrm{CH}_{3}$ group.

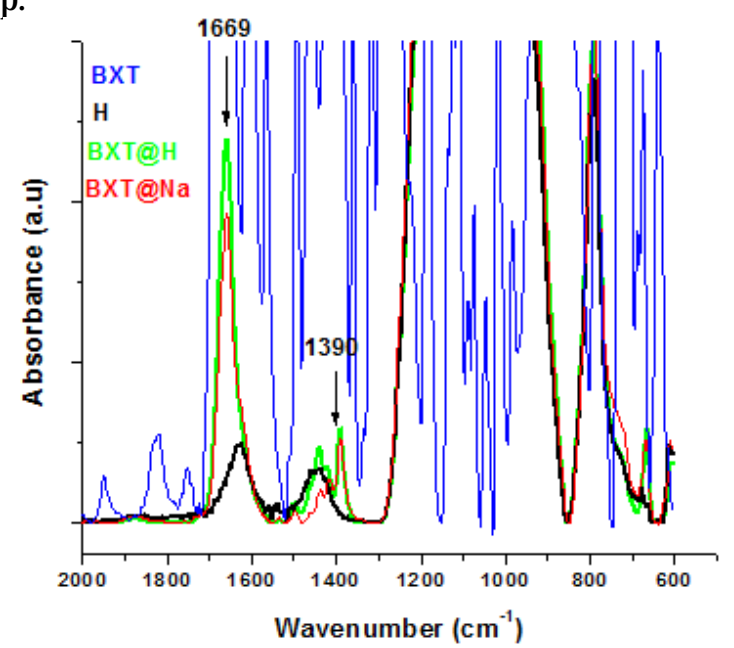

Fig. 3. FTIR spectra characteristic of Bxt@Na and Bxt@H systems as compared to those of Bxt and the zeolitic host

\section{Evaluation of the in vitro release profile of bexarotene from} MRDDS

The results of the in vitro dissolution tests for MRDDSs are shown in figure 4. The experimental data obtained from the in vitro dissolution tests for Bxt in MRDDSs were investigated using the following four mathematical models: zero order kinetics, first order kinetics, the Higuchi model and the Korsmeyer-Peppas model [16-18]. Fitting was done using Matlab 7.1. The criteria used for selecting the most reliable model that could describe the Bxt release profile for each MRDDS were the Akaike Information Criterion (AIC) and the $\mathrm{R}^{2}$ correlation coefficient. In order to achieve a reliable predictive model, the value of the $R^{2}$ correlation coefficient should be as close as possible to 1 and AIC should have the lowest possible values [19]. The obtained results are shown in table 3.

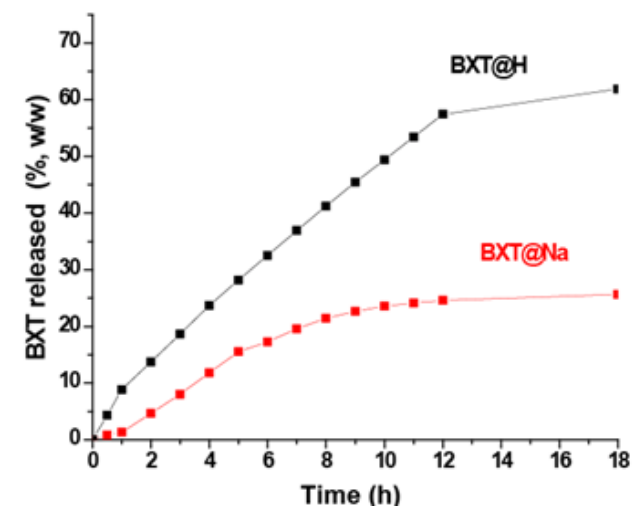

Fig. 4. In vitro release profile of bexarotene in the Bxt@Na and Bxt@H systems 


\begin{tabular}{|c|c|c|c|}
\hline \multirow{2}{*}{ Kinetic model } & \multirow{2}{*}{ Coefficient } & MRDDS & \multirow[b]{2}{*}{ Bxt@H } \\
\hline & & $\mathrm{Bxt@Na}$ & \\
\hline \multirow{3}{*}{ Zero-order } & $\mathbf{K}_{0,}(\mu g / h)$ & 2.0870 & 4.5236 \\
\hline & $\mathbf{R}^{2}$ & 0.7814 & 0.8805 \\
\hline & AIC & 45.7196 & 58.7383 \\
\hline \multirow{3}{*}{ First-order } & $\mathbf{K}_{1,}\left(h^{-1}\right)$ & 0.0237 & 0.0635 \\
\hline & $\mathbf{R}^{2}$ & 0.8558 & 0.9828 \\
\hline & AIC & 39.4785 & 29.6212 \\
\hline \multirow{3}{*}{ Higuchi } & $\mathrm{K}_{\mathrm{H},\left(h^{-0,5}\right)}$ & 6.7538 & 14.4987 \\
\hline & $\mathbf{R}^{2}$ & 0.9065 & 0.9439 \\
\hline & AIC & 32.9734 & 47.4011 \\
\hline \multirow{4}{*}{$\begin{array}{c}\text { Korsmeyer- } \\
\text { Peppas }\end{array}$} & $\mathbf{N}$ & 5.4298 & 9.3094 \\
\hline & $\mathrm{K}_{\mathrm{P},\left(\boldsymbol{h}^{-n}\right)}$ & 0.7 & 0.7 \\
\hline & $\mathbf{R}^{2}$ & 0.9249 & 0.9771 \\
\hline & AIC & 31.6937 & 35.9318 \\
\hline
\end{tabular}

Table 2

THE RESULTS OF FITTING THE IN VITRO RELEASE RATE CURVES FOR BXT IN THE STUDIED SYSTEMS Bxt@Na AND Bxt@H
MRDDSs based on monocationic clinoptilolite behave differently both in terms of the amount of Bxt released and the release mechanism. The Bxt@H system releases $61.89 \%$ of the loaded Bxt in $18 \mathrm{~h}$ and the Bxt@Na system only $25.66 \%$ of the loaded Bxt.

The Bxt@H system follows a Fickian diffusion mechanism, due to the fact that the release rate curve is well described by the first kinetic model, whereas the Bxt@Na system shows a mechanism by abnormal transport by diffusion processes and the release rate is a function of time (fitting to the Korsmeyer-Peppas model).

The crystalline structure of the two CLI samples is the same, but the compensation cations differ in volume and hydration sphere, occupying different volumes in the pore system and inducing an electrostatic field of different intensity. Therefore, Bxt release is strongly influenced by the compensation cations present in the zeolitic channel system.

\section{Conclusions}

In the present study, clinoptilolite from volcanic tuff mined in the Mirsid quarry, Salaj, and purified by thermal and chemical treatment was ionically modified to obtain the $\mathrm{Na}^{+}$monocationic form and the $\mathrm{H}^{+}$monocationic form, respectively, which were investigated as a carrier for the antineoplastic agent bexarotene, used in modified release drug delivery systems (MRDDSs) for the treatment of cutaneous T-cell lymphoma.

The in vitro release profile of MRDDSs with bexarotene was analyzed by fitting the kinetic curves to four mathematical models used in the evaluation of modifiedrelease therapeutic systems.
It has been shown that the prolonged drug release from the studied MRDDs is due to the unique structural properties of clinoptilolite and to the monocationic form that was used.

In the Bxt@Na system and the Bxt@H system, respectively, bexarotene molecules are adsorbed on the non-crystalline active structures, leading to the improvement of Bxt water solubility (enhancing the dissolution rate of poorly water soluble bexarotene) and thereby the availability of the drug.

The results of the present study show that the unique structure, texture properties, chemical nature and internal surface of the matrix of purified natural clinoptilolite is a highly efficient carrier for the studied antineoplastic agent and the obtained MRDDSs are promising in biomedical applications, especially in topical therapies.

Acknowledgments: This study was performed under Partnerships in Priority Areas Program - PN II, developed with the support of MEN UEFISCDI, project PNII-PT-PCCA-2013-4-2024 (TOP-CTCL).

\section{References}

1.QU, L., TANG, X., Cancer Chemotherapy Pharmacology, 65, no. 2, 2010, p. 201.

2. ORTATATLI, M., OGUZ, H., HATIPOGLU, F., KARAMAN, M., Res. Vet. Sci., 78, no. 1, 2005, p.61.

3. OGUZ, H., Eurasian J. Vet. Sci., 27, no. 1, 2011, p. 1.

4. TOPASHKA-ANCHEVA, M., BELTCHEVA, M., METCHEVA, R., ROJAS, J.A., RODRIGUEZ-DE LA FUENTE, A.O., GERASIMOVA, T,, RODRIGUEZ-FLORES L.E., TEODOROVA, S.E., Biol. Trace Elem. Res., 147, no. 1-3, 2012, p. 206.

5. RIVERA, A., RODRIGIEZ-FUENTES, G., ALTSHULER, E., Micropor. Mesopor. Mat., 40, 2000, p. 173. 
6. RODRIGUEZ-FUENTES, G., BARRIOS, M.A., IRAIZOZ, A., PERDOMA, I., CEDRE, B., Zeolites, 19, 1997, p. 441.

7. RIVERA, A., RODRIGIEZ-FUENTES, G., ALTSHULER, E., Micropor. Mesopor. Mat., 24, 1998, p. 51.

8. RODRIGUEZ-FUENTES, G., DENIS, A.R., ALVAREZ, M.A.B., COLARTE, A.I., Micropor. Mesopor. Mat., 94, 2006, p. 200.

9. PAVELIC, K., HADZIJA, M., BEDRICA, LJ., PAVELIC, J., DIKIC, I., KATIC, M., KRALJ , M., HERAK-BOSNAR, M., KAPITANOVIC, S., POLJAKBLAZI, M., KRIZANEC, S., STOJKOVIC, R., JURIN, M., SUBOTIC, B., COLIC, M., J ournal of Molecular Medicine, 78, no. 12, 2001, p. 708.

10. PAVELIC, K., KATIC, M., SVERKO, V., MAROTTI, T., BOSNJAK, B., BALOG, T., STOJKOVIC, R., RADACIC, M., COLIC, M., POLJAK-BLAZI, M., J ournal of Cancer Research and Clinical Oncology, 128, no. 1, 2002, p. 37.

11. STIRBU, I., VIZUREANU, P., CIMPOESU, R., DASCALU, G., GURLUI, S.O., BERNEVIG, M., BENCHEA, M., CIMPOESU, N., POSTOLACHE, P., Journal of Optoelectronics and Advanced Materials, 17, no.7-8, 2015, p. 1179

12. *** http://www.iza-structure.org/databases/
13. CHEN, L., WANG, Y., ZHANG, J., HAO, L., GUO, H., LOU, H., ZHANG, Di., European Journal of Pharmaceutics and Biopharmaceutics, 87, 2014, p. 160.

14. GOGINENI, R.P., (2014). Rapid liquid chromatography uv detection method development and validation of multiclass drugs in active pharmaceutical ingredients and pharmaceutical dosage forms and applicability to biological matrices. PhDthesis. Acharya Nagarjuna University. Available at: http://hdl.handle.net/10603/31065 (Accessed: 11 August 2016).

15. ROUQUEROL, F., ROUQUEROL, J., SING, K., Adsorption by Powders and Porous Solids, Principles, Methodology and Applications. Acad. Press, San Diego, 1999.

16. AHUJA, N., OM, P.K., SINGH, B., Eur. J. Pharm. and Biopharm, 65, 2007, p. 26.

17. OCHIUZ, L., GRIGORAS, C., POPA, M., Molecules, 21, 2016, p. 858. 18. POSTOLACHE, P., PETRESCU, V., DUMITRASCU, D.D., RIMBU, C., VRINCEANU,N.,CIPAIAN,C.R., Chemical Engineering Communications, 203, no. 5, 2016, p. 649.

19. GOHEL, M.C., SARVAIYA, K.G., SHAH, A.R., BRAHMBHATT, B.K., Indian J. Pharm. Sci., 71, 2009, p. 142

Manuscript received: 8.01 .2017 